\title{
Incident HIV during pregnancy and early postpartum period: a population-based cohort study in a rural area in KwaZulu- Natal, South Africa
}

Terusha Chetty $^{1,2^{*}}$, Alain Vandormael ${ }^{1,3}$, Claire Thorne ${ }^{4}$ and Anna Coutsoudis ${ }^{5}$

\begin{abstract}
Background: The evidence on the effect of pregnancy on acquiring HIV is conflicting, with studies reporting both higher and lower HIV acquisition risk during pregnancy when prolonged antiretroviral therapy was accessible. The aim of this study was to assess the pregnancy effect on HIV acquisition where antiretroviral therapy was widely available in a high HIV prevalence setting.

Methods: This is a retrospective cohort study nested within a population-based surveillance to determine HIV incidence in HIV-uninfected women from 15 to 49 years from 2010 through 2015 in rural KwaZulu-Natal. HIV incidence per 100 person-years according to pregnancy status (not pregnant, pregnant, to eight weeks postpartum) were measured in 5260 HIV-uninfected women. Hazard ratios (HR) were estimated by Cox proportional hazards regression with pregnancy included as a time varying variable.

Results: Overall, pregnancy HIV incidence was 4.5 per 100 person-years ( $95 \% \mathrm{Cl} 3.4-5.8)$, higher than non-pregnancy (4.0; $95 \% \mathrm{Cl} 3.7-4.3$ ) and postpartum incidences (4.2 per 100 person-years; $95 \% \mathrm{Cl}$ 2.3-7.6). However, adjusting for age, and demographic factors, pregnant women had a lower risk of acquiring HIV (HR 0.4; 95\% Cl 0.2-0.9, $P=0.032)$ than non-pregnant women; there were no differences between postpartum and non-pregnant women (HR 1.2; $95 \% \mathrm{Cl} 0.4-3.2 ; P=0.744)$. In models adjusting for the interaction of age and gravidity, pregnant women under 25 years with two or more pregnancies had a 2.3 times greater risk of acquiring HIV than their older counterparts (95\% Cl 1.3-4.3; $P=0.008)$.

Conclusions: Pregnancy had a protective effect on HIV acquisition. Elevated HIV incidence in younger women appeared to be driven by those with higher gravidity. The sexual and biological factors in younger women should be explored further in order to design appropriate HIV prevention interventions.
\end{abstract}

Keywords: Pregnancy, Postpartum, HIV incidence, Seroconversion, Adolescents

\section{Background}

In sub-Saharan Africa, HIV risk is greatest among women of reproductive age [1], with relatively high HIV1 incidence (0-16.8 events per 100 person-years) during pregnancy and the immediate postpartum period [2]. Evidence is conflicting on the pregnancy effect on HIV

\footnotetext{
* Correspondence: tchetty@africacentre.ac.za

${ }^{1}$ Africa Health Research Institute, KwaZulu-Natal, South Africa

${ }^{2}$ Department of Public Health Medicine, School of Nursing and Public Health,

University of KwaZulu-Natal, Durban, KwaZulu-Natal, South Africa
}

Full list of author information is available at the end of the article acquisition; in Uganda, Zimbabwe and Rwanda, pregnancy increased HIV susceptibility [2-5]. However, in a pooled analysis of six African cohorts, up to 2011, pregnant women had lower HIV acquisition risk than nonpregnant women due to greater concordance with sexual partners during pregnancy versus non-pregnancy [6].

Fertility has declined gradually to 3.5 children per woman among Black South Africans versus 3.2 children per woman nationally [7]. The fertility decline was typified by childbearing postponement and longer birth intervals, due to contraceptive accessibility since the 1970s 
[8]. While fertility in older women is stabilizing, high adolescent fertility rates (65 per 1000 women aged 1519 years) $[7,9]$ and HIV incidence (17.2 per 100 personyears) [10] are consequences of unprotected sexual intercourse. Young South African women have an $80 \%$ lifetime HIV risk [11]. HIV incidence in 15-26 year olds with early adolescent pregnancies in Eastern Cape was 6.0 per 100 person-years [12]. In the pooled analysis mentioned earlier, the pregnancy protective effect on HIV risk was not observed in 15-24 year olds [6]. While there are challenges around pre-exposure prophylaxis (PrEP) use in younger women [13], high HIV incidence in this population highlights the necessity for effective, accessible biomedical interventions.

Women have greater HIV risk with larger mucosal surface areas exposed to infectious fluids and pathogens and potentially more tissue damage during intercourse [5]. Young women are particularly vulnerable to HIV, with cervical ectopy enhancing target cell exposure to trauma and vaginal pathogens [5]. Pregnancy may also facilitate HIV infection through hormonal changes, genital mucosal alterations and sexual behaviour of women and their partners $[3,14,15]$.

South Africa introduced the World Health Organization Option B [16] in 2013 and in 2015 adopted Option B+ and a CD4 $4^{+}$cutoff of $500 \mathrm{cell} / \mathrm{mm}^{3}$ for treatment of HIVinfected patients [17]. In 2016 all HIV-infected patients irrespective of $\mathrm{CD}^{+}$count became eligible for antiretroviral therapy (ART) [18]. Globally, South Africa has the largest number of people on ART, with approximately $45 \%$ of HIV-infected people [95\% confidence interval (CI) 43\%$49 \%]$ on ART in $2014[19,20]$. In KwaZulu-Natal (KZN), HIV incidence fell by $37 \%$ after ART coverage increased from $<10 \%$ to $\geq 40 \%$ [11]. While ART coverage has improved, potentially protecting uninfected partners from HIV [11], few studies have reported lower HIV risk in pregnancy.

The study objective was to explore pregnancy effects on HIV acquisition during widespread ART availability in rural South Africa. A secondary objective was to present HIV incidence trends by pregnancy status, age and year.

\section{Methods}

Data from a retrospective cohort of women aged 1549 years nested within a population-based surveillance were analysed.

\section{Setting}

Since 2000, the Africa Centre has collected demographic and health data through longitudinal surveillance of approximately 90,000 resident and non-resident members in 12,000 households in the Hlabisa sub-district of uMkhanyakhude [21]. The 2011 HIV prevalence was
$38 \%$ among females versus $16 \%$ in males $25-29$ years [22]. HIV incidence peaked at 6.6 per 100 person-years in 24 year old women between 2004 and 2011 [11]. The 2011 ART coverage for 25-49 year old females was 40\%, higher than their male counterparts at 30\% [22].

\section{Household and individual survey eligibility}

Surveillance eligibility includes household members, who may be resident or non-resident members [21]. Residency is defined as living at a physical structure within the surveillance area at a particular time-point [21]. The inclusion of non-resident members is necessary to understand HIV transmission patterns as nonresidents may be subject to differing HIV risk compared to residents [23]. Two surveys are conducted by interview: (i) household surveillance (initially biannual, since 2012 three times per year); and (ii) an annual individual resident survey, including optional individual HIV surveillance for residents' $\geq 15$ years.

During household surveys, a key proxy respondent answers questions about the physical structure, households, individuals and their relationships. New pregnancy data (for resident and non-resident women) are routinely collected at every household survey, with a pregnancy notification form completed by the proxy respondent (who may be a pregnant woman). Pregnancy outcomes are recorded in the pregnancy notification form during proxy respondent interviews at subsequent rounds. Formal pregnancy testing is not conducted in the surveillance area.

Data on prior pregnancies in women of reproductive age (15-49 years) are only collected in individual resident surveys, and not collected by proxy in household surveys. Hence, a perpetually non-resident woman will lack data on prior pregnancies; a current pregnancy will be notified through a pregnancy notification form as above.

The survey intervals mean that most pregnancies in a household should be ascertained, although underascertainment of early miscarriages is likely, as pregnancies are frequently not reported until after the first antenatal visit and/or pregnancy is not disclosed to the household proxy respondent until after the first trimester. Since 2000, there has been an average of 2200 live-births annually in the surveillance [24], with overall, stable fertility rates at about three children per woman [25].

\section{Identifying pregnancy episodes}

Pregnancy episodes began at the last menstrual period and ended at delivery. For women with miscarriages or pregnancy termination, the estimated delivery date reported to the surveillance was used to signify the pregnancy end. All pregnancy episodes to 15-49 year old 
women in the surveillance, including repeat pregnancies, from 01 January 2010 to 31 December 2015 were included. Some pregnancies were ongoing at the end of December 2015.

Live births were defined as infants delivered alive at $\geq 28$ weeks' gestation, regardless of early neonatal death, and still births as infants not alive on delivery (no movement, crying or breathing) at $\geq 28$ weeks. Miscarriages were pregnancies ending at $<28$ weeks. Induced abortions were intentional pregnancy termination either by medical abortion before 20 weeks or through selftermination.

\section{Identification of the outcome measure}

The outcome measure was time to HIV seroconversion for repeat testing women. Repeat testers had at least two HIV tests, the first of which must have been negative to allow observation of any seroconversion, and were tested for HIV in the surveillance through 31 December 2015. In order to infer HIV negative status on the 1 January 2010, only those with their HIV negative test after 2008 were included. Survival time of HIV-uninfected women began on 1 January 2010 as the pregnancy exposure status started on this date. Follow-up time started from date of the first negative test, until exit at the last test date or seroconversion, if earlier. As the interval between HIV tests was more than a full gestation pregnancy, actual seroconversion time was uncertain. A seroconversion date was therefore randomly imputed between the latest HIV negative test and earliest HIV positive test dates [26].

\section{Statistical analyses}

Woman data were split into non-pregnancy, pregnancy, and eight weeks postpartum episodes. The postpartum period was based on assumptions that pregnancy biological, behavioural and hormonal effects would revert to pre-pregnancy states after approximately six to eight weeks [27, 28].

Crude HIV incidence rates and 95\% confidence intervals by pregnancy status were calculated according to calendar year and age.

The relationship between pregnancy and incident HIV was assessed using Cox proportional hazards regression analysis of time to HIV. Variables considered a priori to be important, age (15-24 years; $25-49$ years) and gravidity (no pregnancies, one pregnancy, two or more pregnancies), were retained in multivariable models $[6,12,29]$. Participant characteristics at last survey date, including education level (less than one year, at least primary school, secondary and beyond, and unknown), residence area (rural, peri-urban, urban), residency (resident, non-resident, non-resident prior to residency), distance from level one road, distance from nearest clinic and distance from nearest primary school, women's HIV status knowledge (yes, no, refused), knowledge (i.e. have heard) about ART (yes, no, refused) were included as potential confounding factors. Pregnancy order was the surveillance recorded count of earlier live births, plus one for the current pregnancy (first born, second/third born, fourth born or later, none, including women never pregnant). Pregnancy order, infant number at delivery (all stillborn; singleton live born or twins, with one live born; multiple births e.g. twins, both live born, or triplets, with two live born), pregnancy outcome (abortion/ stillbirth/miscarriage, singleton live birth, multiple live births, not pregnant) were time varying covariates. In univariable analysis the marginal effect of each variable on HIV acquisition hazard was assessed. Univariate variables with $P<0.2$ were included in the multivariable models; variables with $P<0.05$ were retained in the final model. To examine whether age modified the association between pregnancy and HIV acquisition, an interaction term for age (15-24 years; 25-49 years) and pregnancy was included.

Additional analyses were also performed on the final multivariable model: (i) redefining age into five year intervals; and (iii) testing two variables, age and gravidity, for effect modification on pregnancy and HIV acquisition. All statistical analyses were conducted using Stata 13.1.

\section{Ethics approval and consent to participate}

Ethics approval for household (E009/00) and individual surveillance (BF233/09) is annually recertified at the University of KwaZulu-Natal Biomedical Research Ethics Committee. Either the household head or a proxy in the absence of the household head provides verbal consent for household surveillance. Consent is verbal as general demographic questions are not invasive. Written informed consent is obtained from participants in the individual surveillance, including HIV testing. Data are anonymized for privacy and confidentiality.

\section{Results}

There were 5260 women in the study population (Fig. 1); 1621 reported pregnancies during the study. At the earliest HIV negative test, median age was 24 years (interquartile range (IQR): 19-36 years).

\section{Characteristics of the pregnancy exposure groups during follow-up}

Women contributed 23,050 episodes: 18,095 nonpregnant episodes (78.5\%), 3003 pregnancy (13.03\%), and 1952 postpartum episodes (8.47\%). Resident women contributed more pregnancy episodes $(89.84 \%)$ than non-resident women (10.12\%) (Table 1). Pregnancy was 


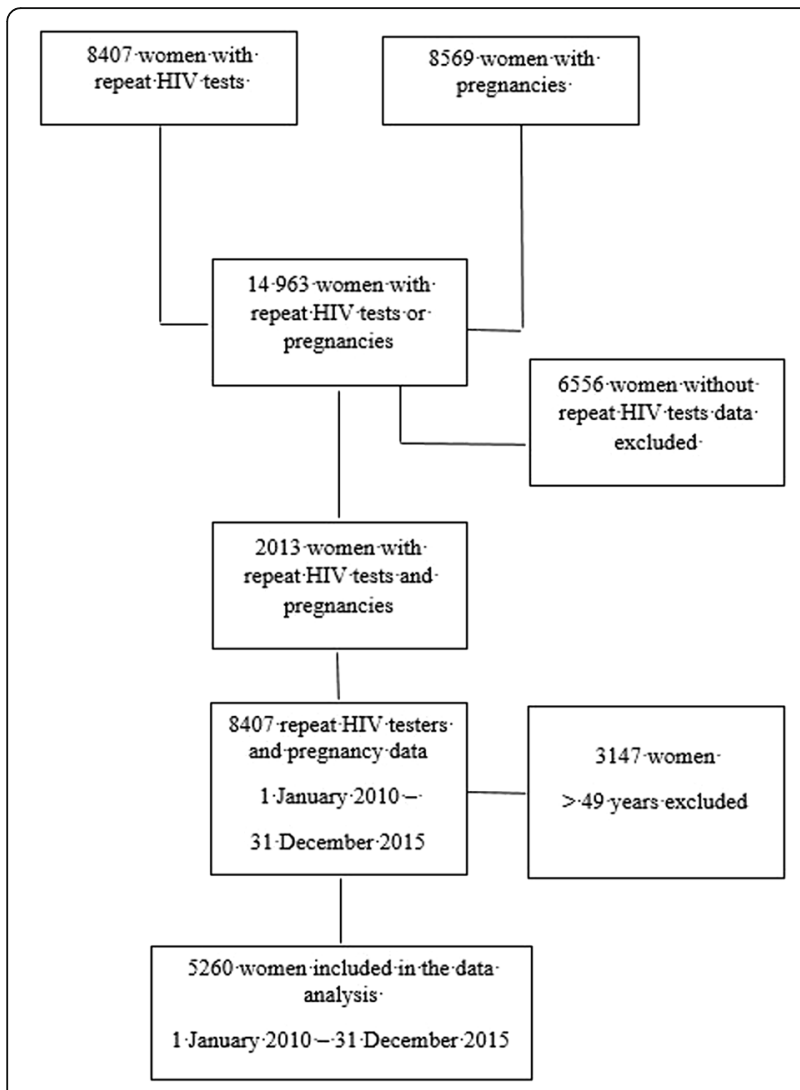

Fig. 1 Flow diagram of study inclusions and exclusions

commoner among younger women (15-24 years), those with secondary and higher education, and women in rural settings. The number of pregnancy episodes with first versus second pregnancies was approximately similar and most pregnant women had reported two or more pregnancies (including the current pregnancy). Women were more likely to know their HIV status during pregnancy and postpartum episodes than in their nonpregnant state. ART knowledge was similar across groups (Table 1).

\section{Incident HIV-1 infections by year and pregnancy exposure groups}

There were 632 HIV seroconversions recorded over 15,711 person-years of follow-up, with an unadjusted incidence rate of 4.02 per 100 person-years. Of the 632 incident infections, 55 occurred during pregnancy (4.5 per 100 person-years; 95\% CI 3.4-5.8), 11 were postpartum (4.2 per 100 person-years; 95\% CI 2.3-7.6), and 566 during non-pregnancy (4.0 per 100 person-years; 95\% CI 3.7-4.3).

In non-pregnant adolescents and young women, HIV incidence steadily increased from 5.03 events per 100 person-years in 2010 peaking at 11.88 events per 100 person-years in 2015 (Table 2). HIV incidence in
Table 1 Time-varying and time-invariant participant characteristics by pregnancy category

\begin{tabular}{|c|c|c|c|}
\hline Characteristic & $\begin{array}{l}\text { Not pregnant } \\
(n=18,095 \\
\text { episodes) } \\
n(\%)\end{array}$ & $\begin{array}{l}\text { Pregnant } \\
\text { ( } n=3003 \\
\text { episodes) } \\
n(\%)\end{array}$ & $\begin{array}{l}\text { Postpartum } \\
\text { ( } n=1952 \\
\text { episodes) } \\
n(\%)\end{array}$ \\
\hline \multicolumn{4}{|l|}{ Time-varying } \\
\hline Age $15-24$ years & 7595 (41.97) & $1794(59.74)$ & $1089(55.79)$ \\
\hline \multicolumn{4}{|l|}{ Time-invariant: Sociodemographic } \\
\hline \multicolumn{4}{|l|}{ Episode Type $^{a}$} \\
\hline Resident & $16,745(92.54)$ & $2698(89.84)$ & $1776(90.98)$ \\
\hline Non-resident & $1281(7.08)$ & $304(10.12)$ & $175(8.97)$ \\
\hline Non-resident prior to residency & $69(0.38)$ & $1(0.03)$ & $1(0.05)$ \\
\hline \multicolumn{4}{|l|}{ Home setting ${ }^{a}$} \\
\hline Peri-urban & $4971(27.47)$ & $849(28.27)$ & $547(28.02)$ \\
\hline Rural & $11,502(63.56)$ & $1956(65.13)$ & $1282(65.68)$ \\
\hline Urban & $614(3.39)$ & $81(2.70)$ & $59(3.02)$ \\
\hline Unknown & $1008(5.57)$ & $117(3.90)$ & $64(3.28)$ \\
\hline $\begin{array}{l}\text { Mean distance from level } 1 \\
\text { road (standard deviation), } \mathrm{km}^{\mathrm{a}}\end{array}$ & $12.7(22.0)$ & $11.2(18.9)$ & $10.7(17.6)$ \\
\hline \multicolumn{4}{|l|}{ Maternal education ${ }^{a}$} \\
\hline Less than one year & $805(4.45)$ & $27(0.90)$ & $19(0.97)$ \\
\hline At least primary school & $2223(12.29)$ & $173(5.76)$ & $126(6.45)$ \\
\hline Secondary and beyond & $13,391(74.0)$ & $2602(86.65)$ & $1678(85.96)$ \\
\hline Unknown & $1676(9.26)$ & $201(6.69)$ & $129(6.61)$ \\
\hline \multicolumn{4}{|l|}{ Time-varying: Pregnancy } \\
\hline \multicolumn{4}{|l|}{ Pregnancy order } \\
\hline First born & $0(0)$ & 796 (40.93) & $708(40.50)$ \\
\hline Second/third born & $0(0)$ & $790(40.62)$ & $710(40.62)$ \\
\hline Fourth or later & $0(0)$ & $359(18.46)$ & $330(18.88)$ \\
\hline Not pregnant & $6479(100)$ & $0(0.0)$ & $0(0)$ \\
\hline \multicolumn{4}{|l|}{ Time-varying: Pregnancy } \\
\hline \multicolumn{4}{|c|}{ Number of live born infants at delivery } \\
\hline No births & $18,095(100)$ & $31(1.03)$ & $19(0.97)$ \\
\hline Singleton & $0(0.00)$ & $2902(96.64)$ & $1885(96.57)$ \\
\hline Multiple births & $0(0.00)$ & $70(2.33)$ & $48(2.46)$ \\
\hline \multicolumn{4}{|l|}{ Time-invariant: Pregnancy } \\
\hline \multicolumn{4}{|l|}{ Gravidity $^{\mathrm{b}}$} \\
\hline None & $2691(14.87)$ & $0(0)$ & $0(0)$ \\
\hline One pregnancy & $4678(25.85)$ & $943(31.40)$ & $597(30.58)$ \\
\hline Two or more pregnancies & $10,726(59.28)$ & $2060(68.60)$ & $1355(69.42)$ \\
\hline \multicolumn{4}{|l|}{ Time-invariant: HIV status \& knowledge } \\
\hline \multicolumn{4}{|l|}{ Knows HIV status } \\
\hline Yes & $13,780(76.15)$ & $2533(84.35)$ & $1649(84.48)$ \\
\hline No & $3478(19.22)$ & $355(11.82)$ & $229(11.73)$ \\
\hline Missing & $837(4.63)$ & $115(3.83)$ & $74(3.79)$ \\
\hline \multicolumn{4}{|l|}{ Heard about ART } \\
\hline Yes & $15,581(86.11)$ & $2669(88.88)$ & $1742(89.24)$ \\
\hline No & $443(2.45)$ & $50(1.67)$ & $33(1.69)$ \\
\hline Missing & $2071(11.45)$ & $284(9.46)$ & $177(9.07)$ \\
\hline
\end{tabular}

${ }^{a}$ Characteristic quantified at the last visit

${ }^{\mathrm{b}}$ Gravidity includes all pregnancies (prior and current) reported by a participant 
Table 2 HIV incidence during pregnancy and non-pregnancy episodes by year and age per 100 person-years (PY)

\begin{tabular}{|c|c|c|c|c|c|c|c|c|}
\hline \multirow[b]{3}{*}{ Year } & \multicolumn{4}{|l|}{ Not pregnant } & \multicolumn{4}{|l|}{ Pregnant } \\
\hline & \multicolumn{2}{|l|}{$15-24$} & \multicolumn{2}{|l|}{$25-49$} & \multicolumn{2}{|l|}{$15-24$} & \multicolumn{2}{|l|}{$25-49$} \\
\hline & $\begin{array}{l}\text { Number of } \\
\text { seroconversion (PY) }\end{array}$ & $\begin{array}{l}\text { HIV incidence } \\
(95 \% \mathrm{Cl})\end{array}$ & $\begin{array}{l}\text { Number of } \\
\text { seroconversion (PY) }\end{array}$ & $\begin{array}{l}\text { HIV incidence } \\
(95 \% \mathrm{Cl})\end{array}$ & $\begin{array}{l}\text { Number of } \\
\text { seroconversion (PY) }\end{array}$ & $\begin{array}{l}\text { HIV incidence } \\
(95 \% \mathrm{Cl})\end{array}$ & $\begin{array}{l}\text { Number of } \\
\text { seroconversion(PY) }\end{array}$ & $\begin{array}{l}\text { HIV incidence } \\
(95 \% \mathrm{Cl})\end{array}$ \\
\hline 2010 & 105 (2089.16) & $5.03(4.15-6.09)$ & $44(2147.42)$ & $2.05(1.52-2.75)$ & $11(255.69)$ & $4.30(2.38-7.77)$ & $0(121.62)$ & 0 \\
\hline 2011 & 70 (1374.23) & $5.09(4.03-6.44)$ & $51(1813.90)$ & $2.81(2.14-3.70)$ & 15 (178.99) & $8.38(5.05-13.90)$ & $1(109.56)$ & $0.91(0.13-6.48)$ \\
\hline 2012 & 57 (971.10) & $5.87(4.53-7.61)$ & $50(1624.24)$ & $3.08(2.33-4.06)$ & $6(141.48)$ & $4.24(1.91-9.44)$ & $1(101.96)$ & $0.98(0.14-6.96)$ \\
\hline 2013 & $43(641.05)$ & $6.71(4.97-9.04)$ & $50(1381.22)$ & $3.62(2.74-4.78)$ & $12(98.4)$ & $12.20(6.93-21.47)$ & $2(77.31)$ & $2.59(0.65-10.34)$ \\
\hline 2014 & 37 (400.34) & $9.24(6.70-12.76)$ & $36(1131.51)$ & $3.18(2.29-4.41)$ & $3(51.78)$ & $5.79(1.87-17.96)$ & $2(70.20)$ & $2.85(0.71-11.39)$ \\
\hline $2015^{\mathrm{a}}$ & $16(134.70)$ & $11.88(7.28-19.39)$ & $7(510.57)$ & $1.37(0.65-2.88)$ & $2(8.12)$ & $24.63(6.16-98.48)$ & $0(14.62)$ & 0 \\
\hline
\end{tabular}

a Some pregnancies in the later part of 2015 would be reported in the first surveillance round in 2016 when women disclose their pregnancy to the household or attend antenatal care; hence 2015 may not include all women who were pregnant in 2015

pregnant younger women showed a more variable pattern, increasing from 4.3 per 100 person-years in 2010 to 12.2 in 2013 , dropping to 5.79 per 100 person-years in 2014, then increasing again to 24.63 per 100 personyears in 2015. Notably, there were relatively wide confidence intervals after 2012. Postpartum, younger women experienced relatively fewer seroconversions compared to non-pregnant or pregnancy states (Table 3).

The HIV incidence estimates in women 25 years and older were lower in all pregnancy categories across years versus respective younger women counterparts (Table 2, Table 3).

\section{Models of HIV acquisition risk}

The crude analysis showed no evidence of different HIV acquisition risks by pregnancy status (Table 4). There were no differences in HIV incidence by pregnancy outcome. In univariable analysis, increasing age (continuous) was protective for HIV acquisition [hazard ratio (HR) $0.94 ; 95 \%$ CI $0.93-0.95 ; P<0.001$ ] (data not shown); when age was categorized, younger women had a 2.4-fold greater hazards of acquiring HIV versus older women (Table 4).

In the multivariable model, adjusting for age, and demographic factors, a statistically significant protective effect existed for pregnancy relative to non-pregnancy episodes (Table 4). Postpartum, women had a 1.2 times greater risk of acquiring HIV relative to non-pregnant women; this did not reach statistical significance. When adjusting for pregnancy and other covariates, younger women had a 2.5 -fold greater risk of acquiring HIV versus older women $(P<0.001)$.

There was an interaction, by age and pregnancy, when adjusting for covariates, just reaching statistical significance (Table 4). Pregnant adolescents and young women were 2.3 times more likely to acquire HIV versus older non-pregnant women. The hazard ratios showed a slight protective effect for adolescent and younger women in the postpartum period versus older non pregnant women; this did not reach statistical significance.

The number of prior pregnancies also significantly increased HIV acquisition risk relative to no prior pregnancies. Moreover, there seemed to be a dose-response relationship between gravidity and HIV, with the hazards of acquiring HIV increasing with additional pregnancies.

Other covariates significantly associated with increased HIV acquisition included having a secondary level education relative to less than one year in school, and not knowing HIV status relative to knowledge of HIV status.

In a separate model, including an interaction term for age and gravidity and variables from Table 4, young women and adolescents with two or more pregnancies

Table 3 HIV incidence during the postpartum period by year and age per 100 person-years (PY)

\begin{tabular}{|c|c|c|c|c|}
\hline \multirow[b]{2}{*}{ Year } & \multicolumn{2}{|l|}{$15-24$ years } & \multicolumn{2}{|l|}{$25-49$ years } \\
\hline & Seroconversion (PY) & HIV incidence $(95 \% \mathrm{Cl})$ & Seroconversion (PY) & HIV incidence $(95 \% \mathrm{Cl})$ \\
\hline 2010 & $2(45.96)$ & $4.35(1.09-17.40)$ & $2(27.61)$ & $7.24(1.81-28.96)$ \\
\hline 2011 & $1(36.72)$ & $2.72(0.38-19.33)$ & $0(23.92)$ & 0 \\
\hline 2012 & $2(28.29)$ & $7.07(1.77-28.27)$ & $0(22.14)$ & 0 \\
\hline 2013 & 1 (19.78) & $5.06(0.71-35.89)$ & $0(19.45)$ & 0 \\
\hline 2014 & $0(11.46)$ & 0 & $1(15.58)$ & $6.42(0.90-45.58)$ \\
\hline $2015^{a}$ & $1(4.08)$ & $24.51(3.45-174.02)$ & $1(6.7)$ & $14.92(2.10-105.92)$ \\
\hline
\end{tabular}

${ }^{a}$ Some pregnancies in the later part of 2015 would be reported in the first surveillance round in 2016 when women disclose their pregnancy to the household or attend antenatal care; hence 2015 does not include all women who may have been pregnant in 2015 
Table 4 Risk factors for HIV seroconversion in women in the reproductive age group, South Africa, 2010-2015

\begin{tabular}{|c|c|c|c|c|c|c|}
\hline \multirow[b]{2}{*}{ Effect } & \multicolumn{3}{|c|}{ annadjusted hazard ratio estimates } & \multicolumn{3}{|c|}{${ }^{\mathrm{b}}$ Adjusted hazard ratio estimates } \\
\hline & Point estimate & $95 \% \mathrm{Cl}$ & $P$ value & Point estimate & $95 \% \mathrm{Cl}$ & $P$ value \\
\hline \multicolumn{7}{|l|}{ Pregnancy } \\
\hline Not pregnant & Ref & - & - & Ref & - & - \\
\hline Pregnant & 1.1 & $0.8-1.5$ & 0.420 & 0.4 & $0.2-0.9$ & 0.032 \\
\hline Postpartum & 1.1 & $0.6-1.9$ & 0.871 & 1.2 & $0.4-3.2$ & 0.744 \\
\hline \multicolumn{7}{|l|}{ Age } \\
\hline $25-49$ years & Ref & - & - & Ref & - & - \\
\hline $15-24$ years & 2.4 & $2.0-2.8$ & $<0.001$ & 2.5 & $2.1-3.1$ & $<0.001$ \\
\hline \multicolumn{7}{|l|}{ Gravidity } \\
\hline No pregnancies & Ref & - & - & Ref & & \\
\hline One pregnancy & 1.4 & $1.1-1.9$ & 0.006 & 1.5 & $1.1-1.9$ & 0.004 \\
\hline Two or more pregnancies & 1.0 & $0.8-1.2$ & 0.789 & 1.7 & $1.3-2.2$ & $<0.001$ \\
\hline Number of live born infants at delivery & 1.02 & $1.0-1.03$ & 0.004 & 1.02 & $1.0-1.03$ & 0.033 \\
\hline \multicolumn{7}{|l|}{ Area of residence } \\
\hline Peri-urban & Ref & - & - & Ref & - & - \\
\hline Urban & 0.8 & $0.7-1.0$ & 0.046 & 0.98 & $0.8-1.2$ & 0.870 \\
\hline Rural & 0.94 & $0.6-1.5$ & 0.819 & 1.0 & $0.6-1.6$ & 0.994 \\
\hline \multicolumn{7}{|l|}{ Education level } \\
\hline Less than one year & Ref & - & - & Ref & - & - \\
\hline At least primary education & 1.9 & $1.0-3.7$ & 0.065 & 1.7 & $0.9-3.4$ & 0.122 \\
\hline At least secondary education & 3.2 & $1.7-5.9$ & $<0.001$ & 2.0 & $1.1-3.8$ & 0.035 \\
\hline Unknown & 4.2 & $2.2-8.1$ & $<0.001$ & 3.2 & $1.7-6.3$ & 0.001 \\
\hline Distance to nearest level $1 \mathrm{road}, \mathrm{km}$ & 1.0 & $1.003-1.009$ & 0.063 & 0.98 & $0.97-1.0$ & 0.089 \\
\hline \multicolumn{7}{|l|}{ Knows HIV status } \\
\hline Yes & Ref & - & - & Ref & - & - \\
\hline No & 0.9 & $0.7-1.1$ & 0.364 & 0.94 & $0.8-1.2$ & 0.601 \\
\hline Refused & 1.3 & $0.9-1.8$ & 0.125 & 1.5 & $1.0-2.0$ & 0.025 \\
\hline \multicolumn{7}{|l|}{ Age and pregnancy } \\
\hline Not pregnant, $25-49$ years & Ref & - & - & Ref & - & - \\
\hline Pregnant; $15-24$ years & 2.6 & $1.1-6.1$ & 0.032 & 2.3 & $1.0-5.5$ & 0.056 \\
\hline Postpartum, 15-24 years & 0.6 & $0.2-2.2$ & 0.483 & 0.58 & $0.2-2.0$ & 0.389 \\
\hline
\end{tabular}

${ }^{a}$ Residency type, distance from level 1 clinic and nearest school, have heard about ART, pregnancy order, and pregnancy outcome were not included in the final multivariable model as $P>0.2$ in the univariable analysis

${ }^{\mathrm{b}}$ Adjusted for all listed covariates, gravidity including the most recent pregnancy

had a 2.3 times greater risk of acquiring HIV than older women with no pregnancies (95\% CI 1.3-4.3; $P=0.008$ ), but no increased risk was seen among those having one pregnancy. Although pregnancy relative to nonpregnancy in this model was protective, the confidence interval included $1.0 \quad$ (HR $0.4 ; 95 \%$ CI $0.2-1.0$; $P=0.051)$.

\section{Discussion}

This study explores the population level effects of pregnancy on HIV acquisition during widespread prolonged ART availability in a high HIV prevalence rural setting.
Pregnancy significantly protected against HIV acquisition, while HIV incidence postpartum was somewhat higher (not statistically significant) relative to nonpregnancy. Adolescents and young pregnant women, particularly those with two or more pregnancies, were more likely to acquire HIV than older women.

Approximately $75 \%$ of young HIV-infected people in sub-Saharan Africa are adolescents and young women between 15 and 24 years; women acquire HIV five to seven years earlier than men [30]. The 2.5 fold increased HIV acquisition risk among adolescents and young women relative to older women in our study is 
consistent with another KZN study [31], and in studies of women in the reproductive age group [32, 33]. In Hlabisa, the HIV incidence was highest among 24 year old females [11]. While PrEP has proven effective with good adherence [34], results from the VOICE study highlighted poor adherence among young South African women for oral or vaginal biomedical products [35]. Longer acting interventions and adherence support are necessary to comprehensive HIV strategies that adolescents and young women are able to access and control [36, 37].

Our overall HIV pregnancy incidence was similar to the pooled incidence in the meta-analysis of 19 cohorts (4.7 per 100 person-years; 95\% CI 3.3-6.1 per 100 person-years) [2]. Moreover, there was a rising trend in HIV seroconversions in non-pregnant and pregnant adolescents and young women over the six years in our study.

Our findings are consistent with the ALPHA network pooled analysis from 2001 to 2011, including Africa Centre data, where pregnancy was protective against HIV infection [6]; the authors suggested this was likely due to reduced sexual activity in pregnancy and having a sero-concordant partner throughout the pregnancy. In a restricted analysis using individual Africa Centre data only, there was no difference in HIV acquisition between pregnant and non-pregnant women. The unadjusted incidence rate in our study was lower than that reported in this earlier study, overall, by pregnancy status, and the Africa Centre site [6]. This implies that women in our study may have benefitted from the transmissionreducing effects of improved ART coverage [11].

In another meta-analysis, the increased HIV acquisition risk among pregnant (pooled HR 1.3, 95\% CI 0.52.1) and postpartum women (pooled HR 1.2, 95\% CI 0.7-1.8) relative to non-pregnant/non-lactating women was not significant [2]. Postpartum findings were consistent with our results. Two of the included studies found a significantly increased HIV acquisition risk during pregnancy versus non-pregnancy [38, 39]. There may be several reasons why our study differs from prior studies [2, 3, 38, 40-42]. First, heterogeneous study populations with varying pregnancy rates and HIV prevalence, and study differences in pregnancy diagnoses, and pregnancy and postpartum classifications may complicate data interpretation. For instance, some studies reported frequent pregnancy tests [38, 41]; our study included proxy report for pregnancies which may have been misclassified, underestimating the pregnancy and postnatal HIV seroconversions. Second, some studies assessed sero-discordant couples, adjusting for reproductive health and sexual behaviours [3, 38, 41]. Our study did not assess these measures due to incomplete information, potentially biasing results away from the null.
While the South African fertility rate has stabilized or declined [7, 25], an estimated $19 \%$ of women in a population-based survey reported an adolescent pregnancy [43]. A substantial proportion of these pregnancies may be unintended within unstable relationships $[44,45]$. Marston et al. found the protective effect of pregnancy on HIV acquisition did not extend to adolescents and young women under 25 years [6], while in Eastern Cape, early adolescent pregnancies were associated with a three-fold HIV risk versus non-pregnancy, as well as higher lifetime partner numbers and having a partner four or more years older [12]. We also showed that adolescents and young women with additional pregnancies had more than two-fold increased incident HIV risk than older non-pregnant women.

Overall, our findings among adolescents and young women are concerning and may reflect structural drivers influencing biomedical intervention use [10]. Emerging evidence suggests that the South African health system is failing to address adolescents' and young women's reproductive needs [46-48]. In response, the South African government has launched a five-pronged strategy to reduce teenage pregnancies and incident HIV in young women [49]. Young women with higher gravidity may face additional barriers due to competing childcare demands, or because they represent a marginalized group. Further research is required to explore pathways through which higher gravidity increases HIV acquisition risk. Fear of pregnancy disclosure and public stigma around teenage pregnancy may prevent early antenatal attendance and HIV service access [50].

Women with higher education attainment were likelier to acquire HIV than those with no education in our study. Though one additional education year reduced the likelihood of acquiring HIV by $7 \%$ in a prior Africa Centre study [51], a systematic review of educational attainment and HIV reported similar results, with higher education levels increasing the HIV acquisition risk, particularly in rural African areas [52].

There may be several pregnancy factors associated with HIV, including behaviour, genital mucosa alterations, and hormonal changes. Data on sexual behaviour and HIV in pregnant women or their partners are scarce. In Uganda, $1 \%$ of pregnant women reported having two or more partners in the previous year, lower than $27 \%$ of non-pregnant women, whereas $36-39 \%$ of male partners of pregnant women reported other sexual partners [3]. Progesterone elevation in late pregnancy are associated with surges in CCR5 co-receptor expression on target cells for HIV-1, potentially increasing HIV acquisition [14]. Pregnancy may also alter cervical immunity through increased pro-inflammatory cytokines levels or decreasing secretory leucocyte protease inhibitors, increasing HIV risk [15]. In young KZN women 
with high HIV prevalence, raised HIV target-cell recruiting chemokines and genital inflammatory cytokines were associated with HIV acquisition [53]. While there was insufficient data to assess these factors, the dose-response relationship of two or more pregnancies may signify behavioural and biological factors may contribute to the HIV vulnerability, especially in younger women [54].

Notable strengths of this study is the inclusion of one of the world's largest HIV incidence cohorts and the ability to capture changing pregnancy status over time, allowing us to assess the effect of additional pregnancies on HIV acquisition.

\section{Limitations}

As some pregnancies starting in late 2015 will be assessed in the first 2016 surveillance round, the 2015 pregnant seroconversions may have been underestimated. We also cannot rule out residual confounding due to inaccurate or incomplete covariate measurement, and were unable to adjust for sexual behaviour, contraception, and sexually transmitted infections (STIs). There is a demonstrated association between STIs and acquiring HIV [55-57]. In a cohort study, including Hlabisa, the baseline STI prevalence in non-pregnant HIV-uninfected women was $13 \%$ and incidence was 20/ 100 person-years [58]. In another KZN study, pregnancy STI prevalence was $32 \%$; there was no difference in any STI prevalence by HIV status [59]. C. trachomatis and $N$. gonorrhoeae are also risk factors for pelvic inflammatory disease which may cause infertility [60]. STIs may hence modify the effect of pregnancy on HIV acquisition.

As women display well known reluctance in sexual partnership reporting, we were also unable to reliably link partner data [61]. As ART access expanded, individuals' awareness of their HIV-infection status may have diminished participant consent in the HIV surveillance $[62,63]$, biasing results. This may be relevant for women tested in antenatal care. As confidence intervals after 2012 were wide in our study, more research is needed to confirm the trend of greater HIV risk in younger women and the associated factors. This study is generalizable to other rural pregnant populations in sub-Saharan Africa.

\section{Conclusions}

This study supports prior data of the lower population HIV risk during pregnancy and early postpartum period. However, increased HIV acquisition risk in pregnant adolescents and young women in rural KZN, despite widespread ART is concerning, and adds to the debate regarding the need for PrEP in vulnerable populations. The elevated HIV incidence in younger women was associated with higher gravidity and further studies are required to understand the prenatal sexual and biological pathways that may increase HIV risk in this group to design appropriate HIV prevention interventions.

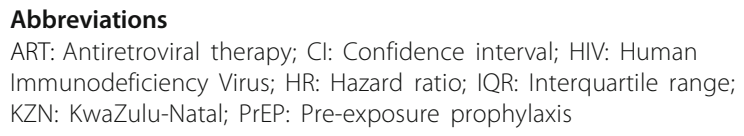

\section{Acknowledgements}

The authors are grateful to Africa Health Research Institute staff, including Kobus Herbst, Tinofa Mutevedzi, and Dickman Gareta, for their support in data management and queries. In particular, the authors would like to thank the women in the surveillance area who contributed their data to this study.

\section{Funding}

The population-based HIV survey and Africa Centre demographic surveillance were supported by Wellcome Trust grants no. 65377 and no. 50535. The principal author was supported by the South African Medical Research Council (SA MRC) Clinician Award for a PhD fellowship. AV was supported the by SA MRC Flagship grant (MRC-RFA-UFSP-01-2013/UKZN HIVEPI).

\section{Availability of data and materials}

The demography, pregnancy and HIV surveillance data that support the findings of this study are available from the Africa Centre data repository, https://data.africacentre.ac.za/index.php.

\section{Authors' contributions}

$\mathrm{TC}, \mathrm{CT}$, and AC conceived the study design. TC performed the data analysis, and wrote the first draft. AV assisted and contributed to the data analysis. All authors commented on the results and contributed to all subsequent manuscript drafts. All authors read and approved the final manuscript.

\section{Ethics approval and consent to participate}

Ethics approval for the household (E009/00) and individual health surveillance (BF233/09) is annually recertified at the Nelson R. Mandela School of Medicine, University of KwaZulu-Natal Biomedical Research Ethics Committee. All participant and household data are anonymized to ensure privacy and confidentiality.

\section{Consent for publication}

Informed written consent were obtained from all participants in the individual health surveillance.

\section{Competing interests}

The authors declare that they have no competing interests.

\section{Publisher's Note}

Springer Nature remains neutral with regard to jurisdictional claims in published maps and institutional affiliations.

\section{Author details \\ ${ }^{1}$ Africa Health Research Institute, KwaZulu-Natal, South Africa. ${ }^{2}$ Department of Public Health Medicine, School of Nursing and Public Health, University of KwaZulu-Natal, Durban, KwaZulu-Natal, South Africa. ${ }^{3}$ KwaZulu-Natal Research Innovation and Sequencing Platform (KRISP), College of Health Sciences, University of KwaZulu-Natal, KwaZulu-Natal, South Africa. ${ }^{4} \mathrm{UCL}$ Great Ormond Street Institute of Child Health, University College London, London, UK. ${ }^{5}$ Department of Paediatrics and Child Health, University of KwaZulu-Natal, Durban, KwaZulu-Natal, South Africa.}

Received: 24 November 2016 Accepted: 16 July 2017 Published online: 26 July 2017

\section{References}

1. UNAIDS. The Gap Report. Geneva. 2014. Available from: www.unaids.org/en/ resources/campaigns/2014/2014gapreport/gapreport. Accessed 16 June 2016. 
2. Drake AL, Wagner A, Richardson B, John-Stewart G. Incident HIV during pregnancy and postpartum and risk of mother-to-child HIV transmission: a systematic review and meta-analysis. PLoS Med. 2014;11:e1001608.

3. Gray RH, Li X, Kigozi G, Serwadda D, Brahmbhatt H, Wabwire-Mangen F, et al. Increased risk of incident HIV during pregnancy in Rakai, Uganda: a prospective study. Lancet. 2005:366:1182-8.

4. Munjoma MW, Mhlanga FG, Mapingure MP, Kurewa EN, Mashavave GV, Chirenje $M Z$, et al. The incidence of HIV among women recruited during late pregnancy and followed up for six years after childbirth in Zimbabwe. BMC Public Health. 2010;10:668.

5. Chersich MF, Rees H. Vulnerability of women in Southern Africa to infection with HIV: biological determinants and priority health sector interventions. AIDS. 2008:22:S27-40.

6. Marston M, Newell ML, Crampin A, Lutalo T, Musoke R, Gregson S, et al. Is the risk of HIV acquisition increased during and immediately after pregnancy? A secondary analysis of pooled HIV community-based studies from the ALPHA network. PLoS One. 2013:8:1-9.

7. Moultrie TA, Timaeus IM. The South African fertility decline: evidence from two censuses and a demographic and health survey. Popul Stud. 2003;57:265-83.

8. Moultrie T, Sayi T, Timæus I. Birth intervals, postponement, and fertility decline in Africa: a new type of transition? Popul Stud. 2012;66:241-58.

9. Moultrie TA, McGrath N. Teenage fertility rates falling in South Africa. S Afr Med J. 2007:97:442-3.

10. Karim QA, Kharsany AB, Frohlich JA, Werner L, Mashego M, Mlotshwa M, et al. Stabilizing HIV prevalence masks high HIV incidence rates amongst rural and urban women in KwaZulu-Natal, South Africa. Int J Epidemiol. 2011;40:922-30.

11. Tanser F, Bärnighausen T, Grapsa E, Zaidi J, Newell M-L. High coverage of ART associated with decline in risk of HIV acquisition in rural KwaZulu-Natal, South Africa. Science. 2013;339:966-71.

12. Christofides NJ, Jewkes RK, Dunkle KL, Nduna M, Shai NJ, Sterk C. Early adolescent pregnancy increases risk of incident HIV infection in the Eastern Cape, South Africa: a longitudinal study. J Int AIDS Soc. 2014;17:18585.

13. Hosek S, Celum C, Wilson CM, Kapogiannis B, Delany-Moretlwe S, Bekker L-G. Preventing HIV among adolescents with oral PrEP: observations and challenges in the United States and South Africa. J Int AIDS Soc. 2016;19:21107.

14. Sheffield JS, Wendel GD, Mclntire DD, Norgard MV. The effect of progesterone levels and pregnancy on HIV-1 coreceptor expression. Reprod Sci. 2009;16:20-31.

15. Morrison C, Fichorova RN, Mauck C, Chen P-L, Kwok C, Chipato T, et al. Cervical inflammation and immunity associated with hormonal contraception, pregnancy, and HIV-1 seroconversion. J Acq Immune Defic Syndr. 2014;66:109-17.

16. South African Department of Health. The South African Antiretroviral Treatment Guidelines. Department of Health. 2013. Available from: www. kznhealth.gov.za/medicine/2013_art_guidelines.pdf. ART Treatment Guidelines Final 25 March 2013.pdf. Accessed 16 June 2016.

17. National Department of Health South Africa. National Consolidated Guidelines For The Prevention Of Mother-to-Child Transmission of HIV (PMTCT) And The Management of HIV In Children, Adolescents And Adults. Pretoria. 2015. Available from: http://www.up.ac.za/media/shared/62/ZP Files/art-guidelines-15052015.zp57683.pdf. Accessed 16 June 2016.

18. South African National Department of Health. Re: Implementation of the Universal Test and Treat strategy for HIV Positive patients and differentiated care for stable patients. 2016. Available from: www.sahivsoc.org/ SubHeader?slug=ndoh-and-who-guidelines. 816 Circular UTT Decongestion. Accessed 22 Mar 2017

19. Global Health Observatory Data Repository. GHO | By category | Antiretroviral therapy coverage - Data and estimates by country [Internet] World Health Organization. 2016. Available from: http://apps.who.int/gho/ data/node.main.626?lang=en. Accessed 16 June 2016.

20. Vandormael A, Newell M-L, Bärnighausen T, Tanser F. Use of antiretroviral therapy in households and risk of HIV acquisition in rural KwaZuluNatal, South Africa, 2004-12: a prospective cohort study. Lancet Glob Heal. 2014:2:e209-15.

21. Tanser F, Hosegood V, Bärnighausen T, Herbst K, Nyirenda M, Muhwava W, et al. Cohort profile: Africa Centre demographic information system (ACDIS) and population-based HIV survey. Int J Epidemiol. 2008;37:956-62.

22. Zaidi J, Grapsa E, Tanser F, Newell M-L, Barnighausen T. Dramatic increases in HIV prevalence after scale-up of antiretroviral treatment: a longitudinal population-based HIV surveillance study in rural KwaZulu-Natal. AIDS. 2013; 27:2301-5.
23. Abdool Karim Q, Abdool Karim SS, Singh B, Short R, Ngxongo S Seroprevalence of HIV infection in rural South Africa. AIDS. 1992:6:1535-9.

24. Muhwava W, Nyirenda M. Demographic and socio-economic trends in the ACDIS, monograph no 2. Mtubatuba, South Africa: Africa Centre For Health and Population Studies; 2007.

25. Moultrie TA, Hosegood V, Mcgrath N, Hill C, Herbst K, Newell ML. Refining the criteria for stalled fertility declines: an application to rural KwaZulu-Natal, South Africa, 1990-2005. Stud Fam Plan. 2008;39:39-48.

26. Law CG, Brookmeyer R. Effects of mid-point imputation on the analysis of doubly censored data. Stat Med. 1992;11:1569-78.

27. Haas JS, Jackson RA, Fuentes-Afflick E, Stewart AL, Dean ML, Brawarsky P, et al. Changes in the health status of women during and after pregnancy. Gen Intern Med. 2005;20:45-51.

28. von Sydow K. Sexuality during pregnancy and after childbirth. J Psychosom Res. 1999:47:27-49.

29. Bernasconi D, Tavoschi L, Regine V, Raimondo M, Gama D, Sulgencio L, et al. Identification of recent HIV infections and of factors associated with virus acquisition among pregnant women in 2004 and 2006 in Swaziland. J Clin Virol. 2010;48:180-3.

30. Shisana O, Simbayi LC, Zuma K, Jooste S, Zungu N, Labadarios D, et al. South African national HIV prevalence, incidence and behaviour survey, 2012. Cape Town: HSRC Press; 2014

31. Naicker $N$, Kharsany ABM, Werner $L$, van Loggerenberg F, Mlisana $K$, Garrett N, et al. Risk factors for HIV Acquisition in High Risk Women in a generalised epidemic setting. AIDS Behav. 2015;19:1305-16.

32. Bulterys M, Chao A, Habimana P, Dushimimana A, Nawrocki P, Saah A. Incident HIV-1 infection in a cohort of young women in Butare, Rwanda. AIDS. 1994;8:1585-91.

33. Kumwenda N, Hoffman I, Chirenje M, Kelly C, Coletti A, Ristow A, et al. HIV incidence among women of reproductive age in Malawi and Zimbabwe. Sex Transm Dis. 2006;33:646-51.

34. Baeten JM, Donnell D, Ndase P, Mugo NR, Campbell JD, Wangisi J, et al. Antiretroviral prophylaxis for HIV prevention in heterosexual men and women. N Engl J Med. 2012:367:399-410.

35. Marrazzo JM, Ramjee G, Richardson BA, Gomez K, Mgodi N, Nair G, et al. Tenofovir-based Preexposure prophylaxis for HIV infection among African women. N Engl J Med. 2015;372:509-18.

36. Pilgrim N, Mathur S, Gottert A, Rutenberg N, Pulerwitz J. Building evidence to guide PrEP introduction for adolescent girls and young women. 2016. Washington, DC: Population Council. Available from: www.popcouncil.org/ uploads/pdfs/2016HIV_PrEPGuidanceForAGYW.pdf. Accessed 16 June 2016.

37. Fleischman J, Peck K. Addressing HIV risk in adolescent girls and young women. Washington, DC. 2015. Available from: http://csis.org/ files/publication/150410_Fleischman_HIVAdolescentGirls_Web.pdf. Accessed 16 June 2016.

38. Mugo NR, Heffron R, Donnell D, Wald A, Were EO, Rees H, et al. Increased risk of HIV-1 transmission in pregnancy: a prospective study among African HIV-1-serodiscordant couples. AIDS. 2011;25:1887-95.

39. Ramjee $\mathrm{G}$, Wand $\mathrm{H}$. Population-level impact of hormonal contraception on incidence of HIV infection and pregnancy in women in Durban, South Africa. Bull World Heal Organ. 2012;90:748-55.

40. Wand H, Ramjee G. Combined impact of sexual risk behaviors for HIV seroconversion among women in Durban, South Africa: implications for prevention policy and planning. AIDS Behav. 2011;15:479-86.

41. Reid SE, Dai JY, Wang J, Sichalwe BN, Akpomiemie G, Cowan FM, et al. Pregnancy, contraceptive use, and HIV acquisition in HPTN 039: relevance for HIV prevention trials among African women. J Acq Immune Defic Syndr. 2010;53:606-13.

42. Moodley D, Esterhuizen TM, Pather T, Chetty V, Ngaleka L. High HIV incidence during pregnancy: compelling reason for repeat HIV testing. AIDS 2009:23:1255-9.

43. Mchunu G, Peltzer K, Tutshana B, Seutlwadi L. Adolescent pregnancy and associated factors in South African youth. Afr Health Sci. 2012;12:426-34.

44. Bankole A, Malarcher S. Removing barriers to adolescents' access to contraceptive information and services. Stud Fam Plan. 2010;41:117-24.

45. Schlyter A, Chipeta L, Dellenborg L, Diallo A, Espling M, Lewis D, et al. Body Politics and Women Citizens - African Experiences. Schlyter A, editor. Sida Stud. Sida. 2009. p. 156. Available from: http://www.sida.se/ English/publications/Publication_database/publications-by-year1/2009/ november/body-politics-and-women-citizens-african-experiences/. Accessed 16 June 2016. 
46. Birungi $H$, Obare F, Mugisha JF, Evelia H, Nyombi J. Preventive service needs of young people perinatally infected with HIV in Uganda. AIDS Care. 2009;21:725-31.

47. Birungi $H$, Mugisha JF, Obare F, Nyombi JK. Sexual behavior and desires among adolescents perinatally infected with human immunodeficiency virus in Uganda: implications for programming. J Adolesc Health. 2009;44:184-7.

48. Birungi H, Obare F, van der Kwaak A, Namwebya JH. Maternal health care utilization among HIV-positive female adolescents in Kenya. Int Perspect Sex Reprod Health. 2011;37:143-9.

49. UNAIDS. South Africa launches SheConquers prevention campaign for increased focus on young women and adolescent girls. 2016. Available from: http://www.unaids.org/en/resources/presscentre/featurestories/2016/ july/20160720_sheconquers. Accessed 26 Jul 2016.

50. Hill LM, Maman S, Groves AK, Moodley D. Social support among HIVpositive and HIV-negative adolescents in Umlazi, South Africa: changes in family and partner relationships during pregnancy and the postpartum period. BMC Pregnancy Childbirth. 2015;15:117.

51. Bärnighausen $T$, Hosegood $V$, Timaeus IM, Newell M-L. The socioeconomic determinants of HIV incidence: evidence from a longitudinal, populationbased study in rural South Africa. AIDS. 2007;21:S29-38.

52. Hargreaves JR, Glynn JR. Educational attainment and HIV-1 infection in developing countries: a systematic review. Trop Med Int Heal. 2002;7:489-98.

53. Masson L, Passmore JAS, Liebenberg $L$, Werner L, Baxter C, Arnold KB, et al. Genital inflammation and the risk of HIV Acquisition in Women. Clin Infect Dis. 2015:61:260-9.

54. Dellar RC, Dlamini S, Karim QA. Adolescent girls and young women: key populations for HIV epidemic control. J Int AIDS Soc. 2015;18:19408.

55. Cohen MS. Classical sexually transmitted diseases drive the spread of HIV-1: back to the future. J Infect Dis. 2012;206:1-2.

56. Lewis D. Detection and management of acute HIV infections in patients with sexually transmitted infections: a window of opportunity for HIV prevention within South Africa? South Afr J Epidemiol Infect. 2012;27:149-55.

57. Mlisana K, Naicker N, Werner L, Roberts L, van Loggerenberg F, Baxter C, et al. Symptomatic vaginal discharge is a poor predictor of sexually transmitted infections and genital tract inflammation in high-risk women in South Africa. J Infect Dis. 2012;206:6-14.

58. Naidoo S, Wand H, Abbai NS, Ramjee G. High prevalence and incidence of sexually transmitted infections among women living in Kwazulu-Natal, South Africa. AIDS Res Ther. 2014;11:31.

59. Moodley D, Moodley P, Sebitloane M, Soowamber D, McNaughton-Reyes $\mathrm{HL}$, Groves AK, et al. High prevalence and incidence of asymptomatic sexually transmitted infections during pregnancy and postdelivery in KwaZulu Natal, South Africa. Sex Transm Dis. 2015:42:43-7.

60. Apari P, de Sousa JD, Müller V, Lammel C, Fan J. Why sexually transmitted infections tend to cause infertility: an evolutionary hypothesis. PLoS Pathog. 2014;10:e1004111.

61. Cleland J, Boerma JT, Carael M, Weir S. Monitoring sexual behaviour in general populations: a synthesis of lessons of the past decade. Sex Transm Infect. 2004:80:ii1-7.

62. Bärnighausen T, Tanser F, Malaza A, Herbst K, Newell ML. HIV status and participation in HIV surveillance in the era of antiretroviral treatment: a study of linked population-based and clinical data in rural South Africa. Trop Med Int Heal. 2012;17:e103-10.

63. Reniers G, Eaton J. Refusal bias in HIV prevalence estimates from nationally representative seroprevalence surveys. AIDS. 2009;23:621-9.

\section{Submit your next manuscript to BioMed Central and we will help you at every step:}

- We accept pre-submission inquiries

- Our selector tool helps you to find the most relevant journal

- We provide round the clock customer support

- Convenient online submission

- Thorough peer review

- Inclusion in PubMed and all major indexing services

- Maximum visibility for your research

Submit your manuscript at www.biomedcentral.com/submit 